\title{
Avoidable mortality in Lithuania
}

\author{
Aldona Gaižauskienè, Romualdas Gurevičius
}

\begin{abstract}
Study objective - The study aimed to analyse avoidable mortality in Lithuania as an index of the quality of health care and to assess trends in avoidable mortality from 1970-90.

Setting and participants - All deaths of Lithuanian residents aged between 0 and 64 years between 1970 and 1990 were analysed. Measurements and main results - Twenty seven per cent of all deaths in this age group were avoidable. Avoidable deaths were grouped into preventable and treatable ones. Treatable causes of death accounted for $54 \%$, and preventable, $46 \%$ of avoidable mortality. Time trends showed that general mortality and mortality from avoidable causes of death in this age group were almost stable between 1970 and 1990. Mortality from treatable causes of death fell, while deaths from preventable causes increased. The results in the preventable group were greatly affected by deaths from malignant neoplasms of trachea, bronchus, and lungs. Differences were noted between the sexes in total mortality as well as in avoidable mortality.

Conclusions - Avoidable causes of death are relatively common and, consequently, they are of practical importance for public health and studies of the health care quality in Lithuania. Reorganisation of health care is to be carried out and considerable emphasis will be placed on health education, promotion, and prevention, as primary prevention measures have not been effective thus far.
\end{abstract}

( $(\mathcal{E}$ Epidemiol Community Health 1995;49:281-284)

Many European countries have been involved in developing a new approach to evaluating the health status of the population. The availability of national mortality data in Lithuania enables researchers to apply this approach in their scientific investigations.

The avoidable mortality method was proposed by an American working group chaired by Rutstein for measuring the quality of health care. The philosophy behind this method is that health services influence mortality from some diseases by prevention or treatment. The working group listed about 80 causes of death which, in some age groups, were defined as indicators of the outcome of medical care intervention or, for some health conditions, indicators of national health policies. High death rates from these causes should be a warning signal indicating that in depth studies of the quality of care are needed. A European Union working group has published atlases of regional differences in a number of "avoidable" deaths, ${ }^{12}$ and this method has been used in other studies. ${ }^{3-6}$

The method of "avoidable" mortality applied to the mortality data in Lithuania may be of interest for several reasons. Firstly, during the long Soviet presence detailed mortality statistics were used only for "duty" purposes and were not acceptable to researchers. Limited data appeared in Lithuanian statistical yearbooks and a few publications were issued in the former USSR. Secondly, studies of trends in death rates from different death causes and total mortality as an important part of the epidemiological monitoring of public health have not been developed here. Thirdly, most health status indicators probably reflect the country's socioeconomic problems. Mortality from conditions amenable to medical intervention is believed to reflect, at least partly, the situation of the health services in Lithuania over the past decades of Soviet influence.

This study aimed to evaluate how well this method can be applied to mortality data in Lithuania and to assess trends in "avoidable" mortality over a 21 year period, from 1970 .

\section{Methods}

National data on deaths in Lithuania were obtained from the Lithuanian State Department of Statistics in Vilnius. This department is the central statistical body in Lithuania. For the period of 1970-87 there are aggregated national mortality statistics, based upon the death certificates routinely issued by doctors after the death of every Lithuanian citizen. Since 1988, individual death certification data have been computerised. For the present study data for 1988-90 were derived from tapes supplied to the Lithuanian Health Information Center by the State Department of Statistics.

"Avoidable" causes of death were grouped according to the cause of a death - that is in ICD-9 chapters. The "avoidable" causes of death were also divided into those which were preventable and treatable according to the list published by Rutstein et al. ${ }^{7}$ We have selected 14 conditions which largely cover the Rutstein list. ${ }^{8}$

Crude and age standardised mortality rates for males and females were calculated on the basis of deaths and population data. Analysis was confined to the age group of 0-64 years. A direct adjustment for age was done using the European population as a standard. The rates are expressed as average annual rates per 100000 population. Regression analysis was carried out using the year of death as an independent variable and the death rate as a dependent variable. Several different models of fit were tested including exponential, power, and logarithmic. Finally, because of simplicity of interpretation and relatively good fit, a linear model was selected. Quality of fit was tested by the coefficient of determination $\left(r^{2}\right)$ and detailed examination of residuals. The significance of the average annual percentage change (AAPC) was tested using the Student's two tailed $t$ test. 
Table 1 Number of deaths from avoidable causes, age standardised death rate per 100000 population (European standard), coefficient of determination, and average annual percentage change (AAPC) for the age group 0-64 in Lithuania, 1970-90, in relation to sex

\begin{tabular}{|c|c|c|c|c|c|}
\hline $\begin{array}{l}\text { Causes of } \\
\text { death }\end{array}$ & $\begin{array}{l}\text { No of } \\
\text { deaths }\end{array}$ & $\begin{array}{l}\text { Age standardised } \\
\text { death rate }\end{array}$ & $\begin{array}{l}\text { Coefficient of } \\
\text { determination } r^{2}\end{array}$ & $\begin{array}{l}A A P C \\
(\%)\end{array}$ & $p$ value \\
\hline \multicolumn{6}{|c|}{ All causes of death: } \\
\hline M & 174233 & $672 \cdot 3$ & $0 \cdot 112$ & 0.4 & NS \\
\hline $\mathrm{F}$ & 85086 & $269 \cdot 9$ & 0.099 & -0.2 & NS \\
\hline Total & 259319 & $449 \cdot 7$ & 0.059 & $0 \cdot 2$ & NS \\
\hline \multicolumn{6}{|c|}{ All avoidable causes of death: } \\
\hline M & 45901 & 173.6 & 0.029 & $0 \cdot 2$ & NS \\
\hline $\mathrm{F}$ & 23061 & $73 \cdot 2$ & $0 \cdot 23$ & -0.4 & $*$ \\
\hline Total & 68962 & $118 \cdot 1$ & 0 & 0 & NS \\
\hline \multicolumn{6}{|c|}{ All treatable causes of death: } \\
\hline M & 21079 & 79 & $0 \cdot 396$ & -0.7 & ** \\
\hline F & 17790 & $56 \cdot 8$ & 0.609 & -0.9 & $* * *$ \\
\hline Total & 38869 & 66.8 & 0.527 & -0.8 & $* * *$ \\
\hline \multicolumn{6}{|c|}{ All preventable causes of death: } \\
\hline M & 24822 & $94 \cdot 6$ & $0 \cdot 337$ & 0.9 & ** \\
\hline $\mathrm{F}$ & 5271 & $16 \cdot 4$ & 0.333 & $1 \cdot 3$ & ** \\
\hline Total & 30093 & $51 \cdot 3$ & $0 \cdot 389$ & 1 & ** \\
\hline
\end{tabular}

Table 2 The number of deaths and age standardised death rate per 100000 population for the most common avoidable causes of death by sex, 1970-90

\begin{tabular}{|c|c|c|c|c|c|}
\hline ICD-9 code & Cause of death & $\begin{array}{l}\text { Age group } \\
(y)\end{array}$ & $\operatorname{Sex}$ & $\begin{array}{l}\text { No of } \\
\text { deaths }\end{array}$ & $\begin{array}{l}\text { Age standardised } \\
\text { death rate }\end{array}$ \\
\hline \multicolumn{6}{|c|}{ Treatable causes of death } \\
\hline $\begin{array}{l}010-018, \\
137\end{array}$ & $\begin{array}{l}\text { Tuberculosis including late } \\
\text { effects of tuberculosis }\end{array}$ & $5-64$ & $\begin{array}{l}\mathrm{M} \\
\mathrm{F}\end{array}$ & \multirow{2}{*}{$\begin{array}{r}3418 \\
811 \\
4229 \\
2158\end{array}$} & \multirow{2}{*}{$\begin{array}{r}14 \cdot 9 \\
2 \cdot 8 \\
8 \cdot 2 \\
9 \cdot 2\end{array}$} \\
\hline 180 & $\begin{array}{l}\text { Malignant neoplasms of } \\
\text { the cervix uteri }\end{array}$ & $15-64$ & $\mathbf{F}$ & & \\
\hline 393-398 & $\begin{array}{l}\text { Chronic rheumatic heart } \\
\text { disease }\end{array}$ & $5-44$ & $\begin{array}{l}M \\
F \\
T\end{array}$ & $\begin{array}{r}858 \\
613 \\
1471\end{array}$ & $\begin{array}{l}4 \cdot 7 \\
2 \cdot 9 \\
3 \cdot 7\end{array}$ \\
\hline $460-519$ & All respiratory diseases & $1-14$ & $\begin{array}{l}\mathrm{M} \\
\mathrm{F}\end{array}$ & $\begin{array}{l}481 \\
411 \\
892\end{array}$ & $\begin{array}{l}6 \cdot 2 \\
5 \cdot 5 \\
5 \cdot 9\end{array}$ \\
\hline 493 & Asthma & $5-44$ & $\begin{array}{l}M \\
\text { F } \\
T\end{array}$ & $\begin{array}{r}78 \\
118 \\
196\end{array}$ & $\begin{array}{l}0.4 \\
0.6 \\
0.5\end{array}$ \\
\hline $540-543$ & Appendicitis & $5-64$ & $\begin{array}{l}\mathrm{M} \\
\mathrm{F}\end{array}$ & $\begin{array}{l}141 \\
112 \\
253\end{array}$ & $\begin{array}{l}0 \cdot 6 \\
0 \cdot 4 \\
0 \cdot 5\end{array}$ \\
\hline $550-553$ & Abdominal hernia & $5-64$ & $\begin{array}{l}M \\
F \\
T\end{array}$ & $\begin{array}{r}74 \\
104 \\
178\end{array}$ & $\begin{array}{l}0 \cdot 3 \\
0 \cdot 4 \\
0 \cdot 4\end{array}$ \\
\hline $\begin{array}{l}401-405 \\
430-438\end{array}$ & $\begin{array}{l}\text { Hypertensive and } \\
\text { cerebrovascular diseases }\end{array}$ & $35-64$ & $\begin{array}{l}\mathrm{M} \\
\mathrm{F} \\
\mathrm{T}\end{array}$ & $\begin{array}{r}8157 \\
6923 \\
15080\end{array}$ & $\begin{array}{l}81 \cdot 4 \\
50 \cdot 1 \\
63 \cdot 9\end{array}$ \\
\hline $\begin{array}{l}574,575 \cdot 0 \\
575 \cdot 1\end{array}$ & $\begin{array}{l}\text { Cholelithiasis and } \\
\text { cholecystitis }\end{array}$ & $5-64$ & $\begin{array}{l}\mathrm{M} \\
\mathrm{F} \\
\mathrm{T}\end{array}$ & $\begin{array}{l}129 \\
242 \\
371\end{array}$ & $\begin{array}{l}0 \cdot 6 \\
0 \cdot 8 \\
0 \cdot 7\end{array}$ \\
\hline $630-676$ & $\begin{array}{l}\text { Maternal deaths } \\
\text { Perinatal mortality }\end{array}$ & $\begin{array}{l}\text { All years } \\
0-6 \text { days } \\
+ \\
\text { stillbirths }\end{array}$ & $\begin{array}{l}\mathbf{F} \\
\mathbf{M} \\
\mathbf{F} \\
\mathrm{T}\end{array}$ & $\begin{array}{r}390 \\
7755 \\
5918 \\
13673\end{array}$ & $\begin{array}{l}33 \cdot 7 \\
13 \cdot 1 \\
10 \cdot 5 \\
11 \cdot 8\end{array}$ \\
\hline \multicolumn{2}{|c|}{ Preventable causes of death } & & & & \\
\hline 162 & $\begin{array}{l}\text { Malignant neoplasms of } \\
\text { the trachea, bronchus, and } \\
\text { lung }\end{array}$ & $5-64$ & $\begin{array}{l}\mathbf{M} \\
\mathbf{F} \\
\mathrm{T}\end{array}$ & $\begin{array}{r}9362 \\
1229 \\
10951\end{array}$ & $\begin{array}{r}45 \cdot 6 \\
4 \cdot 4 \\
21 \cdot 7\end{array}$ \\
\hline $\begin{array}{l}571 \cdot 0-571 \cdot 3 \\
571 \cdot 5-571 \cdot 6\end{array}$ & Cirrhosis of liver & $15-64$ & $\begin{array}{l}\text { M } \\
\text { F } \\
T\end{array}$ & $\begin{array}{l}2278 \\
1153 \\
3431\end{array}$ & $\begin{array}{r}12 \cdot 7 \\
4 \cdot 9 \\
8 \cdot 1\end{array}$ \\
\hline E810-E825 & Motor vehicle accidents & $5-64$ & $\begin{array}{l}\mathrm{M} \\
\mathrm{F} \\
\mathrm{T}\end{array}$ & $\begin{array}{r}13182 \\
2889 \\
16071\end{array}$ & $\begin{array}{r}48 \cdot 3 \\
9 \cdot 6 \\
27 \cdot 2\end{array}$ \\
\hline
\end{tabular}

$\mathrm{T}=$ total population

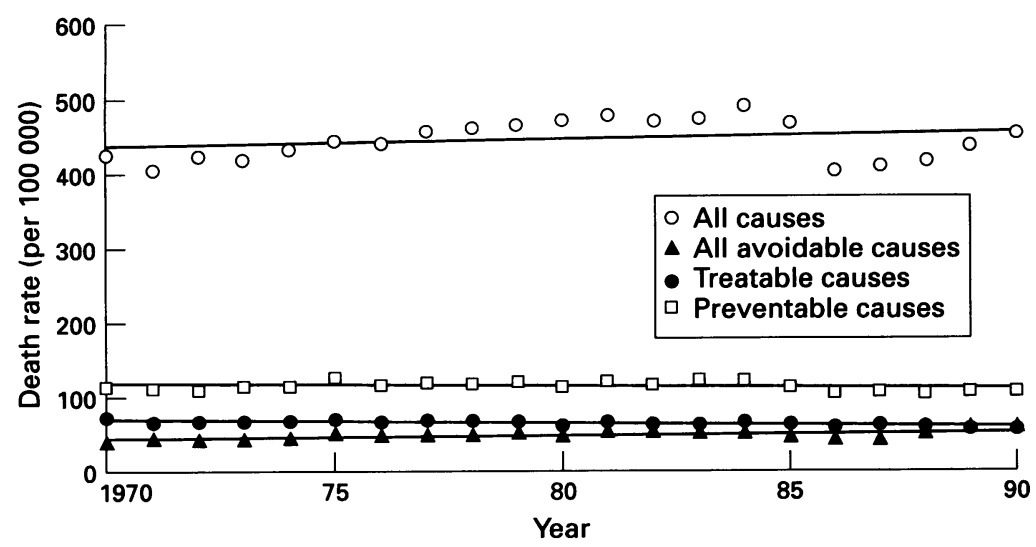

Standardised death rate per 100000 population (European standard) for avoidable causes of death in Lithuania 1970-90.

\section{Results}

Between 1970 and 1990, 174233 deaths occurred in the male population and 85086 in the female population aged $0-64$ years. The avoidable causes of death accounted for $26.6 \%$ of all causes of death in the age group studied (table 1). The proportions of avoidable deaths in relation to all deaths were $26.3 \%$ for males and $27 \cdot 1 \%$ for females. Mortality in this age group was considerably higher for males than females (672.3 and 269.9 per 100000 population, respectively). The same ratio was found for deaths that were regarded as avoidable (173.7 and 73.2 per 100000 respectively). Treatable causes of death accounted for about $56.4 \%$ of all avoidable causes, and preventable causes $43.6 \%$. With regard to avoidable mortality, motor vehicle accidents accounted for the largest proportion - $23.3 \%(28 \cdot 7 \%$ for males and $12.5 \%$ for females) (table 2 ). The second most common category in this group comprised hypertensive and cerebrovascular diseases $(21.9 \%$ : $17 \cdot 8 \%$ for males and $30.0 \%$ for females). Perinatal mortality accounted for $20 \%$ and malignant neoplasms of trachea, bronchus, and lung for $15.9 \%$. Hypertensive and cerebrovascular diseases were the most common treatable causes of death in both sexes (81.4 and 50.1 per 100000 for males and females, respectively). The other most common treatable causes of death were tuberculosis and respiratory diseases in men $(14.9$ and 6.2 per 100000 respectively) and malignant neoplasms of cervix uteri and diseases of respiratory system in women $(9.2$ and 5.5 per 100000 respectively). Large differences were noted between the sexes in selected avoidable causes of death. Mortality from tuberculosis in males was $14.9 \%$ and in females $2.8 \%$; malignant neoplasm of trachea, bronchus, and lung accounted for $45.6 \%$ and $4.4 \%$ respectively; and deaths from motor vehicle accidents comprised $48.3 \%$ and $9.6 \%$ respectively.

The time trend analysis showed that in Lithuania total mortality and mortality from avoidable causes were nearly stable during the period analysed in the present study (table 1 , figure). Trends in mortality from treatable causes of death showed a fall (AAPC $=-0 \cdot 8$, $\mathrm{p}<0.001$ ), while mortality from preventable causes of death rose (AAPC $=0.9, p<0.01)$.

Differences in time trends between sexes were noted. The trend of male mortality from avoidable causes remained nearly stable over the past two decades while for women mortality from avoidable causes decreased by $0.4 \%$ annually.

The trends for different, selected avoidable causes of death were analysed. Because of a relatively small number in certain causes of death groups, statistical significance for annual trends were found only for hypertension and cerebrovascular diseases and lung cancer $(\mathrm{AAPC}=1 \cdot 2$, $\mathrm{p}<0.001, \mathrm{AAPC}=3 \cdot 2, \mathrm{p}<0.001)$.

\section{Discussion}

\section{THE FEASIBILITY OF USING MORTALITY}

STATISTICS

Mortality statistics usually serve as an important measure of public health. Among the key issues in interpreting mortality statistics is the quality of death certification. The general 
Table 3 Crude death rates per 100000 population for avoidable causes of death for 1980-84 in Lithuania, Germany, Denmark, Sweden, and the European Union (EU)

\begin{tabular}{|c|c|c|c|c|c|c|c|}
\hline \multirow[t]{2}{*}{ ICD-9 code } & \multirow[t]{2}{*}{ Cause of death } & \multirow{2}{*}{$\begin{array}{l}\text { Age group } \\
\text { (y) }\end{array}$} & \multicolumn{5}{|c|}{ Crude mortality } \\
\hline & & & Lithuania & Germany & Denmark & Sweden & $E U$ \\
\hline \multicolumn{8}{|c|}{ Treatable causes of death } \\
\hline $010-018,137$ & $\begin{array}{l}\text { Tuberculosis including late effects of } \\
\text { tuberculosis }\end{array}$ & $5-64$ & $6 \cdot 35$ & $1 \cdot 15$ & 0.48 & 0.5 & $1 \cdot 08$ \\
\hline \multirow{3}{*}{$\begin{array}{l}180 \\
393-398 \\
460-519 \\
493 \\
540-543 \\
550-553 \\
401-405, \\
430-438 \\
574,575 \cdot 0, \\
575 \cdot 1 \\
630-676\end{array}$} & $\begin{array}{l}\text { Malignant neoplasms of cervix uteri } \\
\text { Chronic rheumatic heart disease } \\
\text { All respiratory diseases } \\
\text { Asthma } \\
\text { Appendicitis } \\
\text { Abdominal hernia } \\
\text { Hypertensive and cerebrovascular } \\
\text { diseases }\end{array}$ & $\begin{array}{r}15-64 \\
5-44 \\
1-14 \\
5-44 \\
5-64 \\
5-64 \\
35-64\end{array}$ & $\begin{array}{c}4 \cdot 34 \\
3 \cdot 01 \\
4 \cdot 72 \\
0 \cdot 6 \\
0 \cdot 45 \\
0 \cdot 27 \\
65 \cdot 58\end{array}$ & $\begin{array}{c}4 \cdot 74 \\
0 \cdot 18 \\
1 \cdot 7 \\
1 \cdot 08 \\
0 \cdot 19 \\
0 \cdot 16 \\
38 \cdot 09\end{array}$ & $\begin{array}{l}9 \cdot 05 \\
0 \cdot 17 \\
1 \cdot 3 \\
0 \cdot 41 \\
0 \cdot 15 \\
0 \cdot 13 \\
33 \cdot 02\end{array}$ & $\begin{array}{c}4 \cdot 13 \\
0 \cdot 09 \\
0 \cdot 8 \\
0 \cdot 8 \\
0 \cdot 08 \\
0 \cdot 12 \\
28 \cdot 19\end{array}$ & $\begin{array}{c}3.83 \\
0.35 \\
1.98 \\
0.62 \\
0.14 \\
0.2 \\
41.48\end{array}$ \\
\hline & Cholelithiasis and cholecystitis & $5-64$ & 0.5 & 0.44 & $0 \cdot 26$ & 0.31 & $0 \cdot 35$ \\
\hline & $\begin{array}{l}\text { Maternal deaths } \\
\text { Perinatal mortality }\end{array}$ & $\begin{array}{l}\text { All years } \\
0-6 \text { days } \\
+ \\
\text { stillbirths }\end{array}$ & $\begin{array}{l}27 \cdot 73 \\
11 \cdot 4\end{array}$ & $\begin{array}{l}15 \cdot 97 \\
9 \cdot 941\end{array}$ & $\begin{array}{l}5 \cdot 62 \\
8 \cdot 83\end{array}$ & $\begin{array}{l}9 \cdot 76 \\
9 \cdot 76\end{array}$ & $\begin{array}{l}11 \cdot 74 \\
12 \cdot 7\end{array}$ \\
\hline \multicolumn{8}{|c|}{ Preventable causes of death } \\
\hline 162 & $\begin{array}{l}\text { Malignant neoplasms of trachea, } \\
\text { bronchus, and lung }\end{array}$ & $5-64$ & $19 \cdot 36$ & & & $11 \cdot 72$ & \\
\hline \multirow{2}{*}{$\begin{array}{l}571 \cdot 0-571 \cdot 3 \\
571 \cdot 5-571 \cdot 6 \\
\text { E810-E825 }\end{array}$} & Cirrhosis of liver & $15-64$ & $10 \cdot 48$ & & & $10 \cdot 57$ & \\
\hline & Motor vehicle accidents & $5-64$ & $27 \cdot 14$ & & & $10 \cdot 06$ & \\
\hline
\end{tabular}

assessment given to both the census data and vital registration data is relatively good. ${ }^{910}$ The validity of death certificates, however, may vary in different causes of death. Kalediene ${ }^{11}$ compared death certificates with medical records in 25-64 year olds and found discrepancies in $13.2 \%$ of deaths. Cardiovascular and respiratory diseases were over-reported $(12 \cdot 7 \%$ and $7.5 \%$ respectively) and malignant neoplasm was under-reported $(2 \cdot 8 \%)$. On the basis of these findings, we need to remember the possibility of variation in death rates as a result of coding practices and the reliability of death certificates. This problem needs to be improved in Lithuania, but it is nevertheless reasonable to expect that unreliable death certificates explain only a small part of differences in death rates.

Another important methodological question concerning mortality trend analysis is the comparability of death certificates over time: there are difficulties when classification and coding rules are changed. This is most obvious when a new version of the $I C D$ is introduced. In our study we used two versions of the $I C D-I C D$ 8 and 9: the latest one was introduced in Lithuania in 1980 . No change attributable to this has, however, been found in the results shown.

In this study 14 of the most common indicators that are considered amenable to intervention by the health services have been analysed. Hodgkin's disease, which is often used in the analyses of avoidable mortality, was not included in our study. The basic tabulation list of mortality available in Lithuania differs from that used in other countries, and because of this Hodgkin's disease could not be separated from malignant myeloma, lymphosarcoma, reticulosarcoma, and other malignant neoplasms of the lymphoid system. The development of a basic tabulation list similar to that used in the other countries is of great importance for epidemiological surveillance in this country.

AVOIDABLE MORTALITY IN LITHUANIA

The results showed that $26.3 \%$ of deaths in males and $27 \cdot 1 \%$ in females aged $0-64$ years are avoidable. Hence, they were relatively common, and for this reason were of practical importance to public health and studies on the quality of care.

However, this information is not sufficient as a basis for statements about quality of care in Lithuania. According to Donabedian, ${ }^{1213}$ the quality of care should be related to different components of health care. These components are as follows: the structure, the process, and the outcome of care. The structure may refer to the organisation and the resources of health care, the process to the activities of giving and receiving care, and the outcome to the effects of care on the health status of the individual and the population. Studies of the link between different components of care are of importance in validating the assessment of the quality of care. ${ }^{13}$

The use of the concept of avoidable mortality as an outcome indicator has been criticised. ${ }^{16} 17$ The avoidable mortality method is, however, easily available, not expensive, and quick to use. Its application to data in Lithuania is of great value at present as the Lithuanian health care system is in transition. Avoidable mortality could be one of the starting points for assessment of the previous health care system. From this point of view the results of the analyses make more sense, even if they are compared with those of the other countries. Our health care system, like any other system in so-called "socialist countries", was centralised, hospital based, and poorly managed. The resources available for health care were extremely limited (between $3 \%$ and $4 \%$ of the gross national product), and were becoming even more limited because of the critical economic situation. At the same time, the indicators of medical care were much higher than those in the developed countries ( 39 doctors and 122 beds per 10000 population). ${ }^{19}$ Two studies of avoidable mortality in eastern European countries have been published recently, ${ }^{56}$ and it was found that in the age group 0-64 years, mortality from treatable causes fell less quickly here than in developed countries, particularly after $1970 .^{6}$ Our results also showed that mortality from these causes fell very slowly. 
Since the avoidable mortality method is influenced by socioeconomic factors, ${ }^{16} 18$ comparisons with western countries are complicated because of large economic differences. This is of great importance as the Lithuanian health care system is moving more and more towards the model of developed (especially Nordic) countries. Comparisons based on already published data (only crude rates and standardised mortality ratios were published, ${ }^{221}$ and for comparison we selected the crude rates within the same time period and age grouping) did not show an encouraging pattern in Lithuania (table 3). For tuberculosis the Lithuanian death rate was between four and 12 times higher than in developed countries, for respiratory diseases it was between two and five times higher, and for hypertensive and cerebrovascular diseases it was twice as high. The low levels of mortality from treatable conditions presently seen in industrialised countries are likely to reflect, at least partly, the increased effectiveness of the health services. ${ }^{16}$ This shows, indirectly, the ineffectiveness and low level of health quality of the previous health care system. In this respect detailed comparisons would be of great benefit in investigating whether the public health or health care system has failed. In implementing health care reform, however, we have to remember that variations in mortality could result from differences in incidence or case fatality, in certification or in coding practices. Differences in the structure of health care, in its resources as well as in diagnostics and treatment, should be taken into consideration. In analysing certain groups of diseases, it is reasonable to discuss critical mortality rates which indicate that medical care is failing. The avoidable mortality method could be used for screening totals and thus could serve as a warning sign that further in depth studies are needed. ${ }^{20}$

While analysing selected causes of death it was disconcerting to find that mortality from hypertensive and cerebrovascular diseases was increasing. In this connection, cardiologists from Kaunas, collaborating in some international projects (Kaunas-Rotterdam study, CINDI, MONICA project etc) have tried to implement a number of primary prevention measures in relation to these diseases. This has occurred on the local level, that is in Kaunas city and so-called "experimental" regions. It would be of great use if this activity could be extended to cover the whole country.

Death from malignant neoplasms of the trachea, bronchus, and lung influenced the results of the preventable group greatly. The increasing trend in lung cancer mortality, especially for men (AAPC $=3.2, p<0.001$ ) was expected. This type of trend was predicted in 1987 by Gurevičius. ${ }^{14}$ In Lithuania, during recent decades, there have not been any new laws or publicity campaigns against smoking and no programmes have been launched to monitor smoking habits in the population as a whole. Some surveys of selected groups have shed light on the prevalence of smoking in Lithuania. The 1989 survey on the health behaviour of adults indicated that $72 \%$ of men and $15 \%$ of women were daily or occasionally smokers. ${ }^{15}$ Furthermore, the cigarettes used in our country contain much more nicotine and tar than those made in the west. The political and economic changes in Lithuania over the past few years have given us a chance to consider new legislation against smoking. The reorganisation of the Lithuanian health care system has to be carried out with the greatest emphasis placed on health education, promotion, and prevention, however, as our results show that primary prevention measures are still not working in Lithuania. The authors would like to thank Dr Ragnar Westerling, at the
Department of Social Medicine, Uppsala University for his comments.

1 Holland WW, ed. European Community atlas of "avoidable death". Commission of the European Communities Health Services Research Series No 3. Oxford: Oxford Medical Publications, 1988.

2 Holland WW, ed. European Community atlas of "avoidable death". 2nd ed Vol 1. Commission of the European Communities Health Services Research Series No 6. Oxford Oxford Medical Publications, 1991.

3 Westerling R. Trends in "avoidable" mortality in Sweden 1974-85. F Epidemiol Community Health 1992;46:489-93.

4 Paikolainen $\mathrm{K}$, Eskola J. The effect of health services on mortality: decline in death rates from amenable and nonamenable causes in Finland, 1969-1981. Lancet 1986; 199-202.

5 Bohan F, Hajdu P, Belicza E. Avoidable mortality. Is it an indicator of quality of medical care in eastern European countries? Quality Assurance in Health Care 1991;3:191203.

6 Boys RJ, Forster DP, Jozan P. Mortality from causes amenable and non-amenable to medical care: the experience able and non-amenable to medical care: the

of eastern Europe. BMF 1991;303:879-83.
Rutstein DD, Berenberger W, Chalmers TC, Child GC Rutstein DD, Berenberger W, Chalmers TC, Child GC,
Fischmen AP, Perrin EB. Measuring the quality of medical care. N Engl f Med 1976;294:582-8.

8 Westerling R. "Avoidable" causes of death in Sweden 1974 85. Quality Assurance in Health Care 1992;4:319-28.

9 Anderson BA, Silver BD. The changing shape of Sovie mortality, 1958-1985: an evaluation of old and new evidence. Population Studies 1989;43:243-65.

10 Anderson BA, Silver BD. Trends in mortality of Soviet population. Soviet Economy 1990;6:191-251.

11 Kalediene R. The assessment of health status of Lithuania based on mortality statistic. Kaunas: Kaunas Medical School, 1992 (in Russian); 24. (Dissertation.)

12 Donabedian A. The definition of quality: a conceptual exploration. Explorations in quality assessment and moniexploration. Explorations in quality assessment and monitoring. Vol 1. The definition of quality and approaches to its assessment. An

13 Donabedian A. Basic approaches to assessment: Structure, process and outcome. Explorations on quality assessmen and monitoring. Vol I. The definition of quality and approaches to its assessment. Ann Arbor, MI: Health Administration Press, 1980:79-128.

14 Gurevičius R. Methodological aspects and some results of descriptive epidemiology of lung cancer in Lithuania. Vilnius: University of Vilnius, 1987:23 (in Russian). (Dissertation.)

15 Gostautas A, Stanikas T. Tobacco, alcohol, and health. In Lithuania MCMXC, health problems. Kaunas: Medicina, 1993:24 (in Lithuanian)

16 Mackenbach JP, Bouvier-Colle MH, Jougla E. "Avoidable" mortality and health services: a review of aggregate data studies. F Epidemiol Community Health 1990;44:106-11. able mortality and variations in health care resources. Lancet 1987;i:789-92.

18 Poikolainen $\mathrm{K}$, Eskola J. Health services resources and their relation to mortality from causes amenable to health care relation to mortality from causes amenable to health care interven 17 . 9 .

19 Health care and health services in statistical data. Vilnius: Lithuanian Health Information Centre, 1991.

20 Westerling R. The avoidable mortality method. Empirical Westerling R. The avoidable mortality method. Empirical
studies using data from Sweden. Acta Universitatis UPstudies using data
saliensis 1993:69.

21 Westerling R, Smedby B. The European Community "avoidable deaths indicators" in Sweden 1974-1985. In $f$ Epidemiol 1992;21:502-10. 